Article

\title{
Evaluation of Chill Cast Co-Cr Alloys for Biomedical Applications
}

\author{
Ana Laura Ramirez-Ledesma ${ }^{1}$, Hugo F. Lopez ${ }^{2, *}$ and Julio Alberto Juarez-Islas ${ }^{1}$ \\ 1 Instituto de Investigaciones en Materiales, Universidad Nacional Autonoma de Mexico, \\ Av. Universidad 3000, Circuito Exterior S/N, Cd. Universitaria, Mexico D.F. 04510, Mexico; \\ alramirez.unam@gmail.com (A.L.R.-L.); julioalb@unam.mx (J.A.J.-I.) \\ 2 Materials Science and Engineering Department, CEAS University of Wisconsin-Milwaukee, \\ 3200 N. Cramer Street, Milwaukee, WI 53211, USA \\ * Correspondence: hlopez@uwm.edu; Tel.: +1-414-229-6958
}

Academic Editors: Harrie Weinans and Amir A. Zadpoor

Received: 15 April 2016; Accepted: 11 August 2016; Published: 16 August 2016

\begin{abstract}
Binary Co-Cr alloys containing various $\mathrm{Cr}$ contents were vacuum induction melted and cast into wedge-shaped copper molds. It was intended to develop a microstructure (1) free from interdendritic segregation and porosity; (2) having minimal intermetallic precipitates; and (3) suitable for biomedical applications. The resultant microstructures were evaluated from sections obtained longitudinally and centrally in the plane normal to the diverging wedge faces. All ingots showed a dendritic microstructure with some characteristic features. For instance, in Co-20-30 wt. \% Cr alloys, the chilled cast microstructures consisted of columnar dendrites without interdendritic segregation, a minimum of intermetallic precipitates, and the presence of a predominantly athermal HCP $\varepsilon$-martensite ( $>80$ vol. \%). In addition, the metastable FCC $\gamma$-Co phase was identified by X-ray diffraction and scanning electron microscopy. In the case of 35-44 wt. \% Cr cobalt alloys, a eutectic constituent including the $\sigma$-phase were found to develop in the interdendritic regions. From this work, a Co-20 wt. \% Cr alloy was chosen for further investigation after heat treating below the $\gamma / \varepsilon$ transition temperature. The resultant tensile strength and ductility were further improved after applying a heat treatment at $730{ }^{\circ} \mathrm{C}$ for $30 \mathrm{~min}$, obtaining values of elongation of $26 \%$ as compared with $2.55<5$ of elongation in the as cast condition. Also, the alloy corrosion resistance in artificial saliva was investigated. It was found that the exhibited corrosion rates for the as-cast and heat-treated conditions are between those reported for other similar systems.
\end{abstract}

Keywords: cobalt alloys; rapid solidification; athermal martensite; heat treatment; mechanical properties; biomedical alloys

\section{Introduction}

Wrought and investment casting Co-Cr-Mo alloys have been widely employed for implant devices replacing hard tissue or in dental restorations in the human body [1,2]. These alloys are known to possess excellent biocompatibility, mechanical properties, as well as wear and corrosion resistance [3-5]. In as-cast cobalt alloys the solidified microstructures consist of a predominantly FCC $\gamma$-dendritic structure which is accompanied by segregation, and second phase precipitates within the matrix and along the interdendritic regions. In addition, inherent investment casting defects are of concern as they can lead to early implant failure and inadequate mechanical properties [6]. 
In general, investment casting Co-Cr-Mo alloys used as biomedical devices exhibit poor ductility, shrinkage porosity, interdendritic segregation, and the presence of intermetallic compounds $[7,8]$. Hence, in order to improve alloy performance for potential biomedical applications, modifications in alloy design and casting technology have been considered in order to enhance the strength and ductility of Co-based alloys [9]. In particular, changes in alloy design have been aimed at suppressing brittle-phase formation along the interdendritic regions during solidification.

As Co-Cr-Mo devices are expected to experience increasing use in a growing population of young patients, alloy reliability and safety levels become a major concern. Thus, further improvements in the exhibited mechanical properties of Co-alloys are desirable. One of the ways to achieve this goal has been through microstructural control, such as thermomechanical processing or heat-treating [10-14]. In addition, alternatives in alloy design to produce biocompatible-grade Ni-free alloys have been under investigation due to the inherent risks associated with Ni-related allergic responses [15,16].

From the published literature, it is apparent that in order to design a sound Co-based alloy for biomedical applications, the choice of alloying elements, processing conditions and resultant properties need to be clearly identified. In particular, it is desirable to attain optimal alloy strength and ductility, combined with a high corrosion resistance [17]. Accordingly, in this work, a novel approach is proposed that leads to optimum casting processing conditions which result in desirable mechanical properties, including corrosion resistance. The investigated alloys were as-cast segregation-free $\mathrm{Co}-\mathrm{Cr}$ alloys intended for novel biomedical applications. For this purpose, wedge-shaped copper molds were employed in order to vary the cooling rates undergone by the as-cast alloys. The resultant alloy microstructures were subsequently characterized and out of these, the Co-20 wt. \% Cr alloy was chosen for further characterization as they did not exhibit interdendritic segregation and the amount of precipitate was minimal. Moreover, in this alloy the effect of implementing a heat treatment below the $\gamma / \varepsilon$ transition temperature on the mechanical properties and corrosion resistance was evaluated and compared with the as-cast condition

\section{Materials and Methods}

\subsection{Materials Preparation}

Cobalt alloys containing 20, 30, 35, 40, and 44 wt. \% Cr were melted from pure Co (99.99\%) and pure $\mathrm{Cr}(99.99 \%)$ in an alumina crucible using a vacuum induction furnace. Mo was not added because one aim of this work was to achieve a nearly free segregation microstructure with a minimum quantity of precipitates and carbides. The system was evacuated three times with high purity argon prior to vacuum melting. Once the alloy reached $2273 \mathrm{~K}$ (approx. $2000^{\circ} \mathrm{C}$ ), both $\mathrm{Co}$ and $\mathrm{Cr}$ were in liquid state and the chamber was immediately evacuated again to remove any gases dissolved in the liquid bath. At the same time, the temperature was dropped down to $1873 \mathrm{~K}$ (approx. $1600^{\circ} \mathrm{C}$ ) and a slag was formed in the bath surface. Afterwards, the liquid alloy was cast into a wedge-shaped copper mold. The wedge mold sides were covered by an alumina sheet to keep the heat flow predominantly in one direction, (see Figure 1). Prior to casting, $\mathrm{Pt} / \mathrm{Pt}-18 \% \mathrm{Rh}$ thermocouples were centrally inserted into the wedge copper mold at 20,60, and $90 \mathrm{~mm}$ from the tip to the top of the mold cavity, at half thickness locations of 1.0,3.0, and $4.5 \mathrm{~mm}$, respectively. The as-cast ingots were then longitudinally and centrally sectioned in the plane normal to the diverging wedge faces and mechanically polished and electrolitically etched using a 60 vol. $\% \mathrm{HNO}_{3}+40$ vol. $\% \mathrm{H}_{2} \mathrm{O}$ solution and 6 volts. 


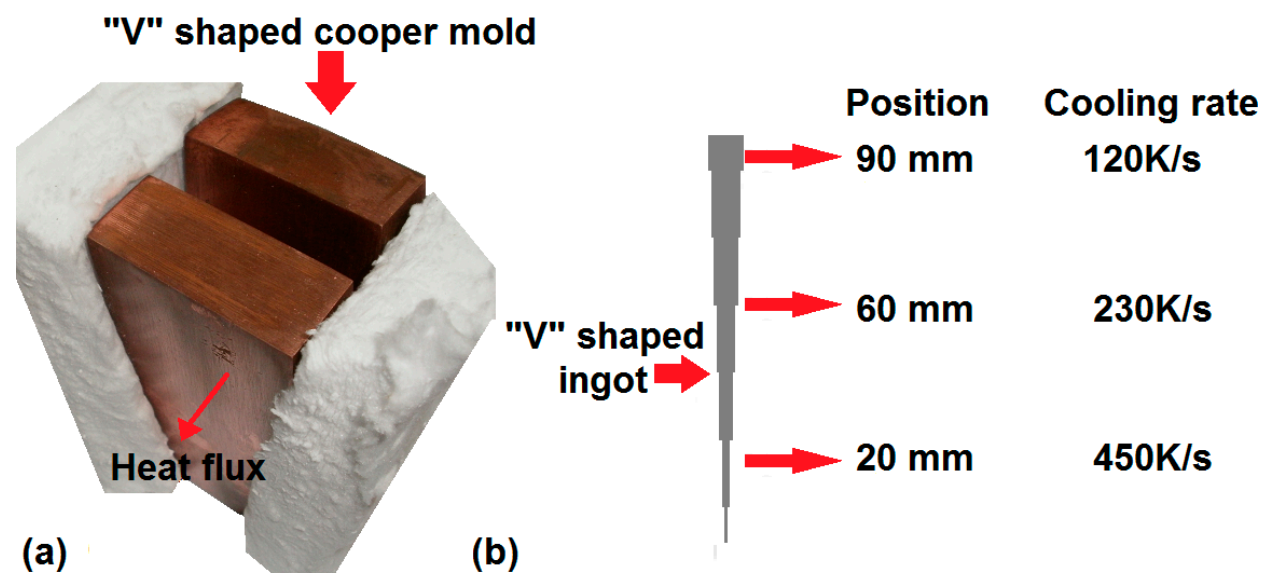

Figure 1. (a) Wedge-shaped copper mold isolated in both sides by an alumina sheet; (b) "V" shaped ingot showing three different cooling rate zones: $90 \mathrm{~mm}$ high: $120 \mathrm{~K} / \mathrm{s}, 60 \mathrm{~mm}$ high: $230 \mathrm{~K} / \mathrm{s}$, and $20 \mathrm{~mm}$ high: $450 \mathrm{~K} / \mathrm{s}$.

\subsection{Materials Characterization}

The resultant microstructures were identified and characterized using a JEOL 7600 scanning electron microscope (SEM, Jeol, Tokyo, Japan) and a JEOL1200 EX, transmission electron microscope (TEM, Jeol, Tokyo, Japan coupled with energy dispersed X-ray microanalysis (EDS, Jeol, Tokyo, Japan). X-ray diffraction was carried out using a Siemens D-5000 diffractometer with a $\mathrm{K} \alpha-\mathrm{Cu}(1.5418 \AA$, Siemens, Munich, Germany) radiation and a scanning angle, $2 \theta$ from $40^{\circ}$ to $96^{\circ}$ at a scanning rate of $1 \% \mathrm{~min}$. Ingot sections of an alloy containing $20 \mathrm{wt}$. \% Cr whose microstructures were dendritic, but segregation suppressed, were selected for heat treating. The implemented heat treatment was carried out at $1003.15 \mathrm{~K}\left(730^{\circ} \mathrm{C}\right)$ for $60 \mathrm{~min}$ under an argon atmosphere [18]. This was followed by determinations of mechanical properties in a tensile testing machine, Instron 1210 (MTS Systems Corporation, Eden Prairie, MN, USA), at a strain rate $\dot{\varepsilon}=1.6 \times 10^{-4} \cdot \mathrm{s}^{-1}$ and a travel speed of $0.5 \mathrm{~mm} / \mathrm{min}$.

\subsection{Electrochemical Techniques}

Preliminary corrosion tests were carried out using potentiodynamic polarization in a Gill AC potentiostat. For this purpose, the applied potential was varied from $-1250 \mathrm{mV}$-with respect to the free corrosion potential, $E_{\text {corr }}-$ up to $1250 \mathrm{mV}$ at a scanning rate of $0.5 \mathrm{mV} / \mathrm{s}$. A conventional three-electrode glass cell was used with graphite as an auxiliary electrode and a saturated calomel electrode (SCE) as the reference. Corrosion current density values, $I_{\mathrm{corr}}$, were estimated using the Tafel extrapolation method and by considering an extrapolation interval of $\pm 250 \mathrm{mV}$ around the $E_{\mathrm{corr}}$ value, once stable. The electrolyte employed consisted of artificial saliva whose composition is given in Table 1.

Table 1. Chemical composition of the artificial saliva.

\begin{tabular}{|c|c|}
\hline Compound & Quantity (g/L) \\
\hline $\mathrm{KH}_{2} \mathrm{PO}_{4}$ & 0.34 \\
\hline $\mathrm{Na}_{2} \mathrm{HPO}_{4} \cdot 2 \mathrm{H}_{2} \mathrm{O}$ & 0.445 \\
\hline $\mathrm{KHCO}_{3}$ & 1.5 \\
\hline $\mathrm{NaCl}$ & 0.585 \\
\hline $\mathrm{MgCl}_{2} \cdot 6 \mathrm{H}_{2} \mathrm{O}$ & 0.0305 \\
\hline Citric acid & 0.0315 \\
\hline $\mathrm{CaCl}_{2}$ & 0.0166 \\
\hline
\end{tabular}




\section{Results}

\subsection{Cooling Rates and Microstructure}

Figure 2a shows cooling curves at various locations of the wedge-shaped mold in the temperature range of $1873.15-1673.15 \mathrm{~K}\left(1600-1400^{\circ} \mathrm{C}\right)$. Notice that the exhibited cooling rates are closely related to the thermocouple locations. In particular, it can be observed that the cooling rate for the Co-20 wt. \% Cr alloy was $450 \mathrm{~K} / \mathrm{s}$ at $20 \mathrm{~mm}$ from the tip (curve 1); $230 \mathrm{~K} / \mathrm{s}$ at $60 \mathrm{~mm}$, center (curve 2); and $120 \mathrm{~K} / \mathrm{s}$ at $90 \mathrm{~mm}$, top (curve 3). In addition, the location of the various solidified microstructures-including a eutectic and other intermetallic phases in the chilled-cast wedges for the various $\mathrm{Cr}$ contents $(20,30,35,40$, and $44 \mathrm{wt}$. \% Cr) - is shown in Figure $2 \mathrm{~b}$. Three dominant microstructures were identified: (1) dendrites; (2) dendrites and a eutectic in the interdendritic region; and (3) dendrites plus a eutectic and the $\sigma$-phase in the interdendritic region; this in agreement with other investigations [19].

(a)

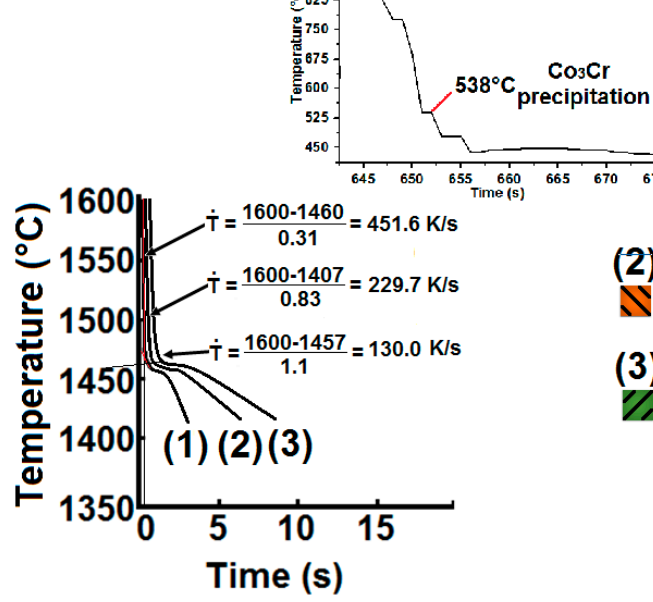

(b)

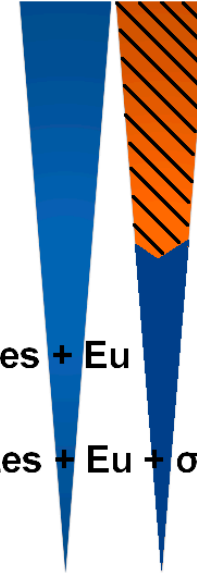

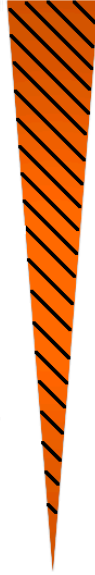

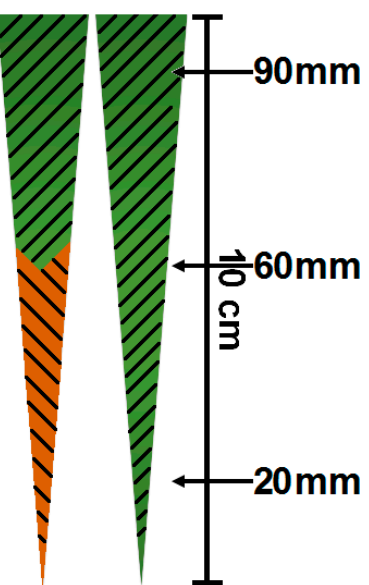

Figure 2. (a) Representative cooling curves exhibited at various locations. (1) Tip; (2) middle; (3) top in a chill-cast wedge of $\mathrm{Co}-20 \mathrm{wt}$. \%Cr alloy. In the inset two solid state events can be seen: (1) the martensitic transformation at $868{ }^{\circ} \mathrm{C}$; and (2) $\mathrm{Co}_{3} \mathrm{Cr}$ precipitation at $538{ }^{\circ} \mathrm{C}$; (b) exhibited microstructures for the Co-20, 30, 35, 40, and $44 \mathrm{wt}$. \% Cr, along the wedge-shaped ingot.

Figure 3 shows the various microstructures found in the Co-Cr alloys located at 20,60, and $90 \mathrm{~mm}$ from the tip to the top of the wedge, respectively. Notice that the dominant solidified microstructures are made up of columnar dendrites. The presence of interdendrite segregation was not detected for $\mathrm{Cr}$ contents $\leq 30 \mathrm{wt}$. \%, indicating that interdendritic segregation and brittle phase formation can be suppressed through rapid solidification.

Figure 4 shows the dimensions of the interdendritic segregation regions in as-cast Co-alloys processed by the investment casting technique $[2,7,20-24]$. Notice that interdendritic segregation regions are on the order of 5-18 $\mu \mathrm{m}$, but in atomized powders the interdendritic segregation diminishes down to close to $0.3 \mu \mathrm{m}$ [25]. 

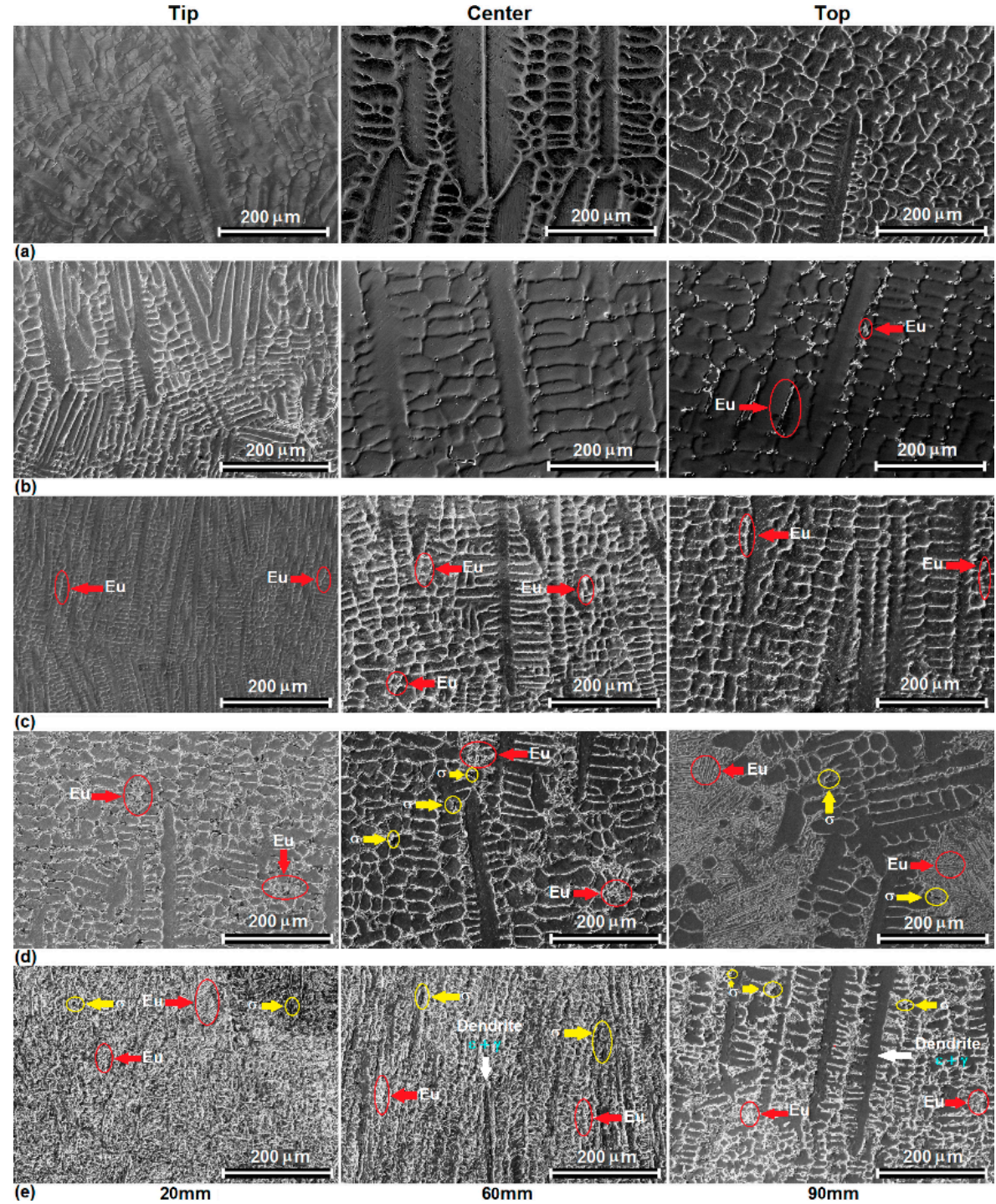

Figure 3. Microstructures found in wedge shaped $\mathrm{Co}-\mathrm{Cr}$ alloy ingots. (a) $\mathrm{Co}-20 \mathrm{wt}$ \% $\mathrm{Cr}$; (b) Co-30 wt. \% Cr; (c) Co-35 wt. \% Cr; (d) Co-40 wt. \% Cr; and (e) Co-44 wt. \% Cr. It is important to note that the heat flux direction is always in the opposite sense with respect to the columnar dendrites growth.

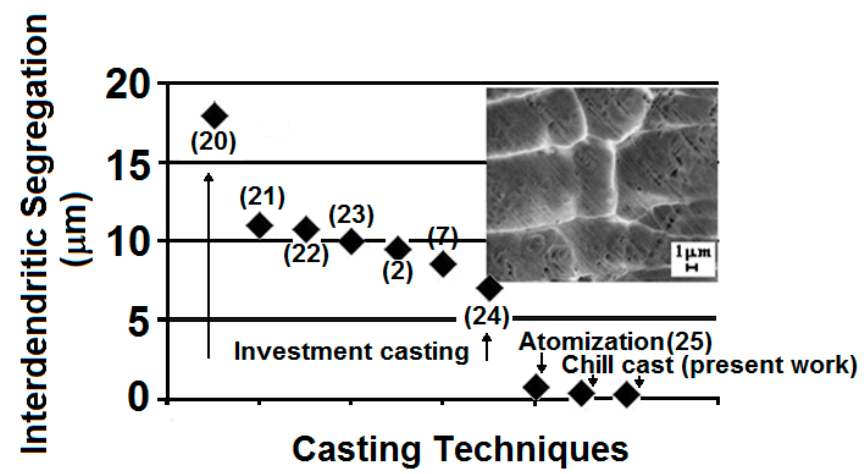

Figure 4. Interdendritic segregation reported in Co-alloys. References are given in parentheses and the chill cast corresponds to the present work. 


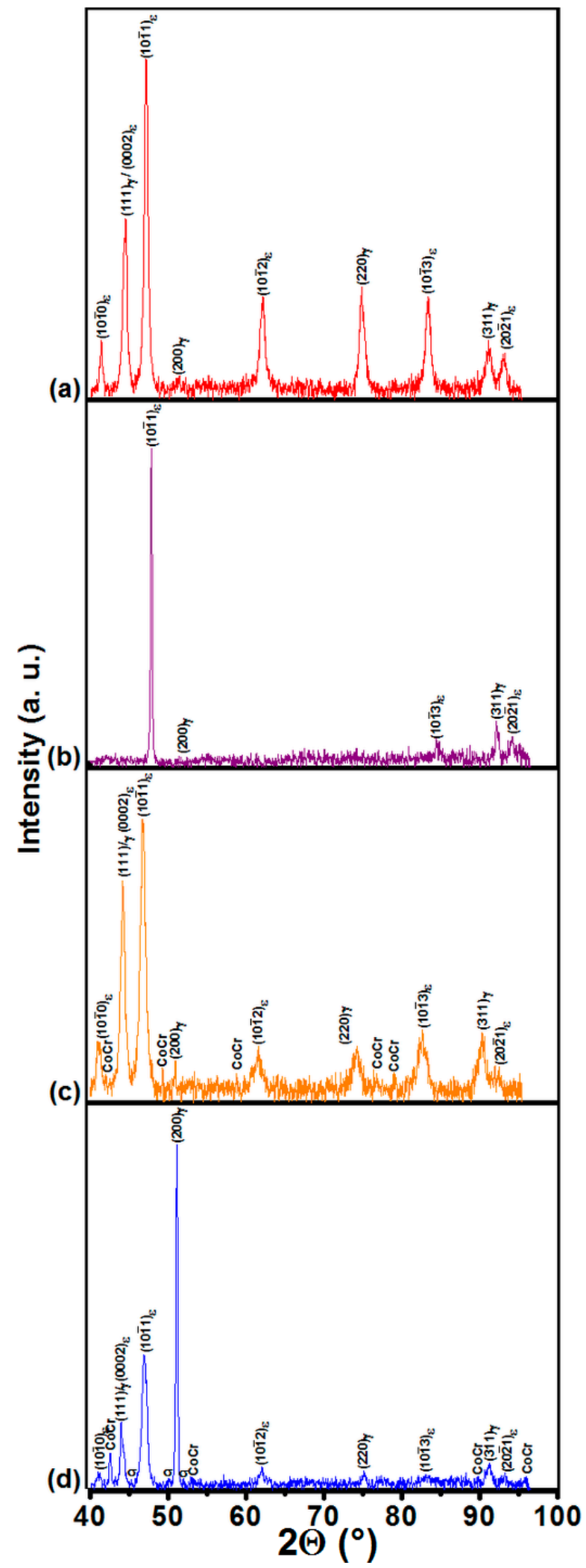

Figure 5. Representative X-ray diffraction patterns for the Co-Cr alloys: (a) Co-20 wt. \% Cr; (b) Co-30 wt. \% Cr; (c) Co-35 wt. \% Cr; (d) Co-40 wt. \% Cr at the center of the wedge-shaped cooper mold. 
In the present work, interdendritic spaces below $0.25 \mu \mathrm{m}$ were observed in the bulk microstructure. In addition, randomly distributed precipitates within the matrix and at interdendritic arms were identified by SEM microanalysis. Accordingly, the $\mathrm{Co}_{3} \mathrm{Cr}$ and $\mathrm{CoCr}$ intermetallic phases were found to precipitate with a volume fraction which varied from $2.4 \times 10^{-3}(20 \mathrm{wt}$. \% Cr) to $2.8 \times 10^{-3}$ (30 wt. \% Cr). Beyond this $\mathrm{Cr}$ content, copious precipitation of $\mathrm{Co}_{3} \mathrm{Cr}$ and $\mathrm{CoCr}$ occurred, so it was no longer possible to make accurate volume fraction determinations (see Figure 3d,e). Moreover, from the X-ray diffraction determinations (see Figure 5), it was found that dendrites were composed of athermal HCP $\varepsilon$-Co phase and metastable FCC $\gamma$-Co phase, and both phases were found to form in all the rapidly solidified alloys regardless of the $\mathrm{Cr}$ content. The amounts of athermal HCP $\varepsilon$-phase were determined by employing the expression proposed by Sage and Guillaud [26]:

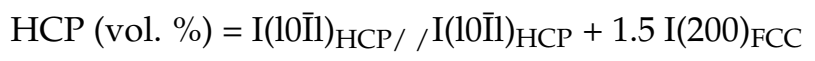

where $\mathrm{I}(200)_{\mathrm{FCC}}$ and $\mathrm{I}(10 \overline{\mathrm{I}})_{\mathrm{HCP}}$ are the integrated intensities of the $(200)_{\gamma}$ and $(10 \overline{\mathrm{I}})_{\varepsilon}$ diffraction peaks for the FCC and HCP phases, respectively.

Accordingly, using the exhibited intensity peaks, the amounts of athermal $\varepsilon$-martensite were estimated as a function of the applied cooling rates and $\mathrm{Cr}$ contents, and they are given in Table 2.

Table 2. Athermal $\varepsilon$-martensite transformation as a function of cooling rates for several Cr contents.

\begin{tabular}{|c|c|c|c|c|}
\hline Cr (wt. \%) & Cooling Rate (K/s) & HCP (wt. \%) & $\mathrm{I}(10 \overline{\mathrm{I}} \mathrm{l})_{\mathrm{HCP}}$ & I (200) $)_{\mathrm{FCC}}$ \\
\hline \multirow{3}{*}{20} & 450 & 82.3 & $184.2^{2}$ & $26.3^{2}$ \\
\hline & 230 & 89.6 & $277.9^{2}$ & $21.3^{2}$ \\
\hline & 120 & 92.6 & $481.8^{2}$ & $25.3^{2}$ \\
\hline \multirow{3}{*}{30} & 450 & 61.6 & $38.37^{2}$ & $15.9^{2}$ \\
\hline & 230 & 90.1 & $77.3^{2}$ & $5.6^{2}$ \\
\hline & 120 & 81.1 & $92.9^{2}$ & $14.3^{2}$ \\
\hline \multirow{3}{*}{35} & 450 & 79.0 & $90.3^{2}$ & $15.9^{2}$ \\
\hline & 230 & 92.1 & $200.5^{2}$ & $11.3^{2}$ \\
\hline & 120 & 81.9 & $145.5^{2}$ & $21.3^{2}$ \\
\hline \multirow{3}{*}{40} & 450 & 81.9 & $51.3^{2}$ & $7.5^{2}$ \\
\hline & 230 & 43.8 & $166.7^{2}$ & $142.2^{2}$ \\
\hline & 120 & 51.5 & $25.1^{2}$ & $15.7^{2}$ \\
\hline
\end{tabular}

From this table, it is evident that in segregation-free alloys, the volume fractions of precipitated $\varepsilon$-phase where were $89.6 \%$ and $90.1 \%$ for $20 \% \mathrm{Cr}$ and $30 \% \mathrm{Cr}$ alloys, respectively. These results are given in Figure 6, where the vol. \% $\varepsilon$-martensite is plotted as a function of alloy processing. In this regard, the percent of $\varepsilon$-Co phase in investment casting alloys exhibits a value between 2 and 12 vol. \% [25,27], while in hot Co-alloy forgings (10\% deformation) the amount of $\varepsilon$-phase reached a value of $35 \mathrm{vol}$ \% [10]. Additionally, in atomized particles and chilled cast alloys (present work), 64 vol. \% and 89.6-90.1 vol. \% $\varepsilon$-phase were precipitated, respectively (Figure 6).

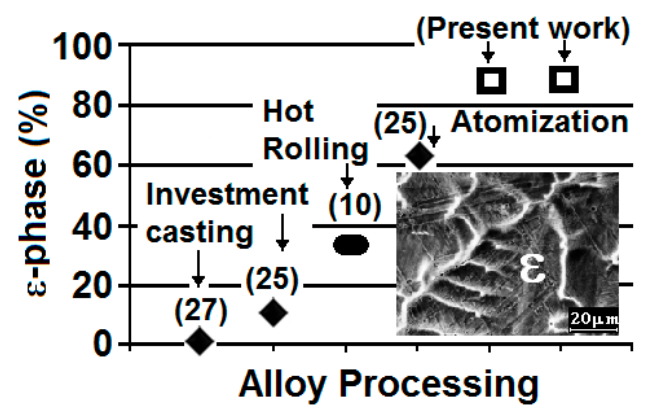

Figure 6. Percent of $\varepsilon$-phase as a function of alloy processing. 
Figure 7 is an SEM micrograph of the athermal $\varepsilon$-martensite developed within the columnar dendritic structure in a Co-20 wt. \% Cr alloy; in particular, notice the typical striations associated with the athermal $\varepsilon$-martensite transformation [28]. The exhibited microstructure was further investigated by TEM means.

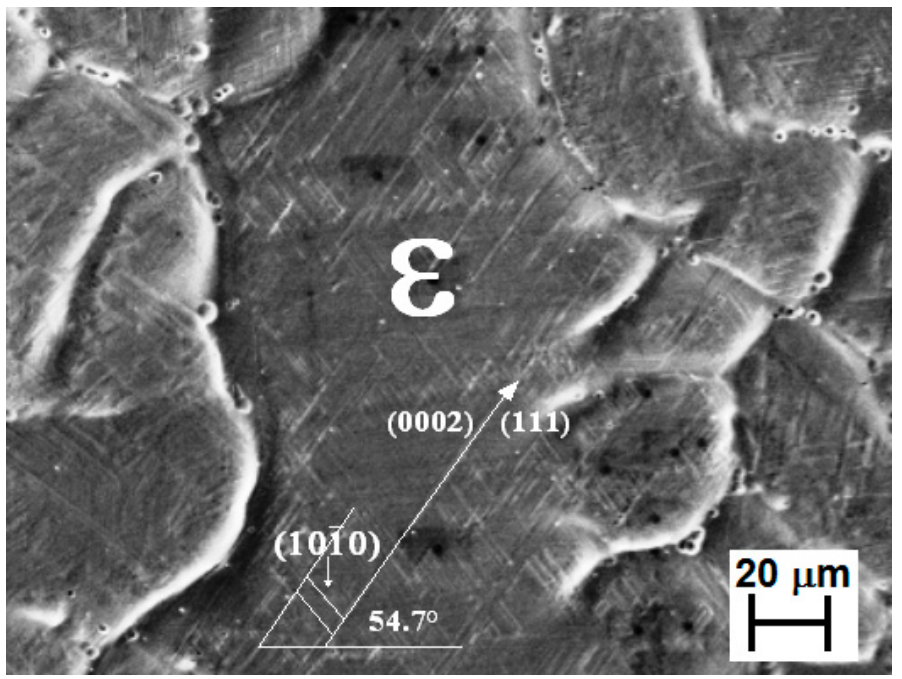

Figure 7. As-cast Co-20 wt. \% Cr microstructure: scanning electron microscope (SEM) micrograph of the FCC $\gamma$-Co dendrites and athermal $\varepsilon$-martensite formed inside the dendrites.

Figure $8 \mathrm{a}$ is a TEM micrograph with its corresponding diffraction pattern (Figure 8b) showing a fine distribution of elongated athermal $\varepsilon$-plates within the columnar dendritic structure.

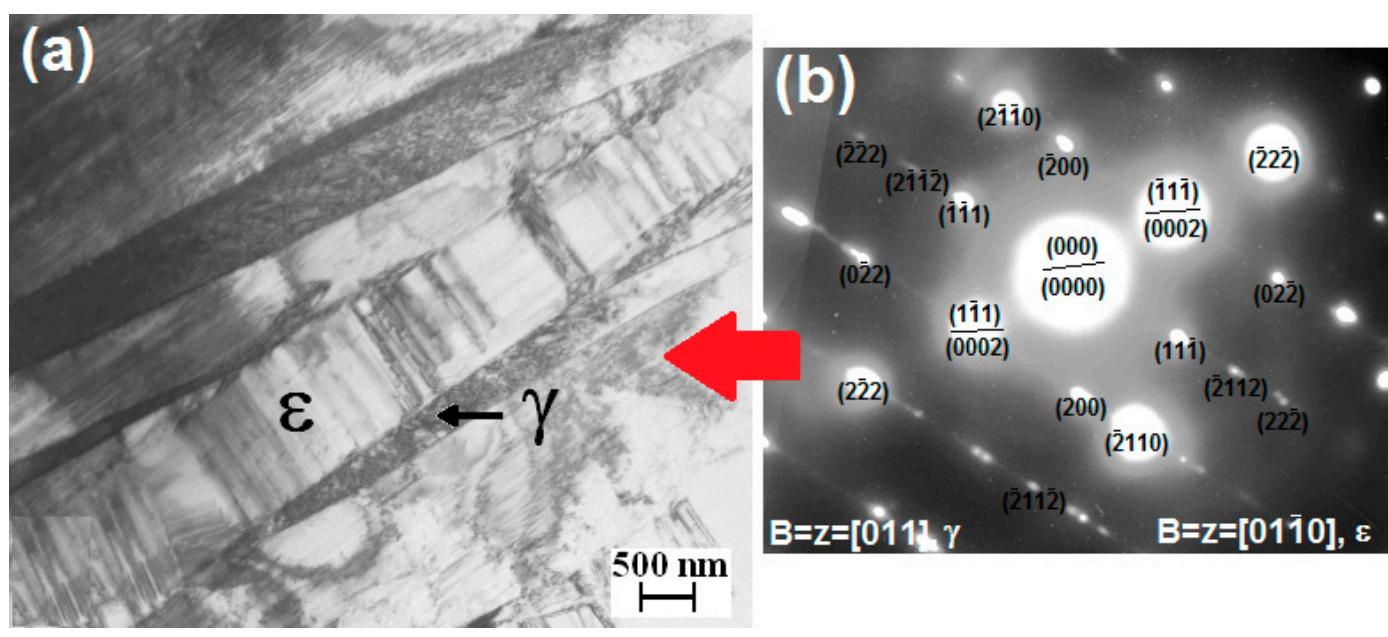

Figure 8. As-cast Co-20 wt. \% Cr: (a) transmission electron microscope (TEM) micrograph showing the presence of FCC $\gamma$-Co phase between the $\varepsilon$-martensite plates; (b) corresponding electron diffraction pattern.

\subsection{Mechanical and Corrosion Properties}

Figure 9 shows stress-strain plots corresponding to the Co-20 wt. \% $\mathrm{Cr}$ alloy in both the as-cast and heat-treated conditions. Notice from this figure that the alloy in the as-cast condition exhibits yield and ultimate tensile strengths of $230 \mathrm{MPa}$ and $361 \mathrm{MPa}$, respectively, but an elongation of only $2.55 \%$. Yet, after isothermal alloy heat treating at $1003.15 \mathrm{~K}$ for $60 \mathrm{~min}$ the mechanical properties 
exhibit a dramatic improvement in alloy strength of over 40\% (i.e., $346 \mathrm{MPa}$ yield strength and a UTS of $597 \mathrm{MPa})$.

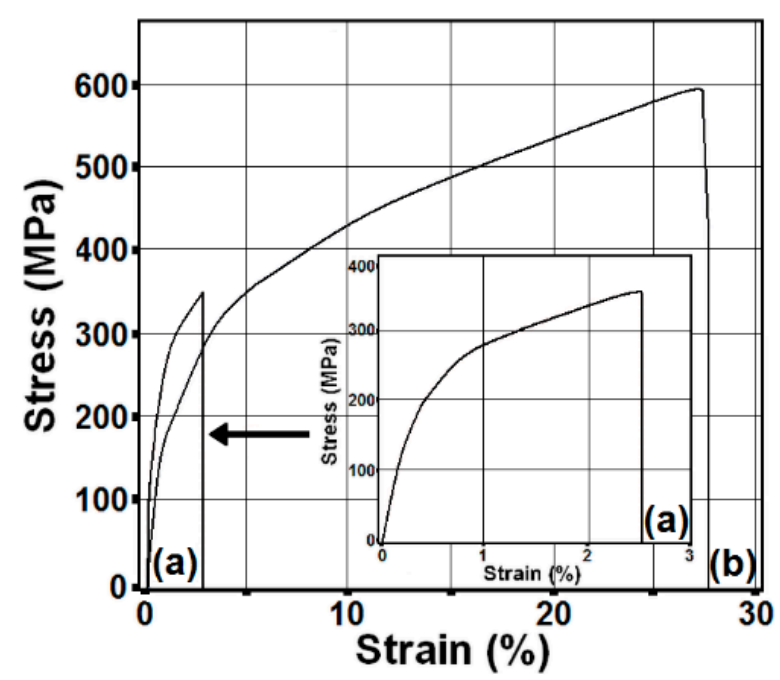

Figure 9. Stress-strain curves for Co-20 wt. \% Cr alloy: (a) in the as-chill cast condition and (b) heat-treated condition.

An examination of the fracture surfaces (see Figure 10a) indicates that the as-cast alloy fractured in a somewhat brittle fashion along columnar interdendritic interfaces. Also, the fracture path shows $\varepsilon$-Co phase striations delineating the columnar dendrites. In contrast, the heat-treated alloy exhibited a highly ductile fracture mode which was accompanied by significant plastic deformation (up to $26 \%$ elongation) and dimple development (Figure 10b).

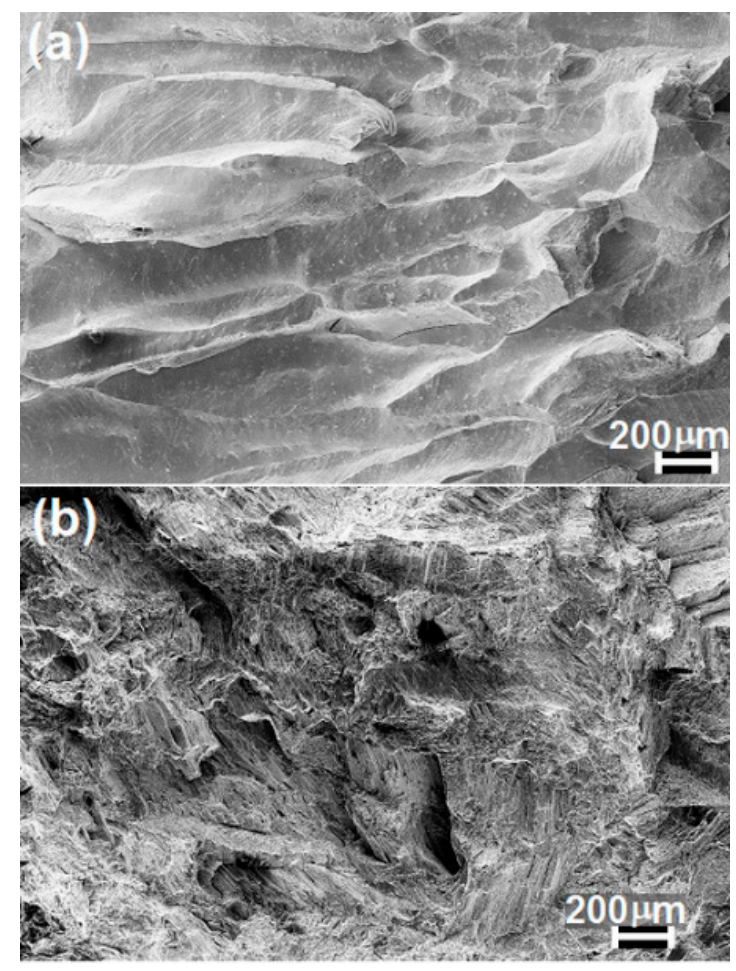

Figure 10. Fractography of Co-20 wt. \% Cr alloy: (a) in the as-chill cast condition and (b) heat-treated condition. 
Finally, preliminary testing on the corrosion resistance of the Co-20 wt. \% Cr alloy by potentiodynamic polarization in synthetic saliva was used for determinations of corrosion rates. Figure 11 and Table 3 show the corrosion potential, current density, and corrosion rate values found for the Co-20 wt. \% Cr alloy in both, the as-cast, and after heat treating conditions. Notice that corrosion rates of $8 \times 10^{-4}$ and $3.56 \times 10^{-3} \mathrm{~mm} /$ year were found for the as-cast and treated alloys, respectively.

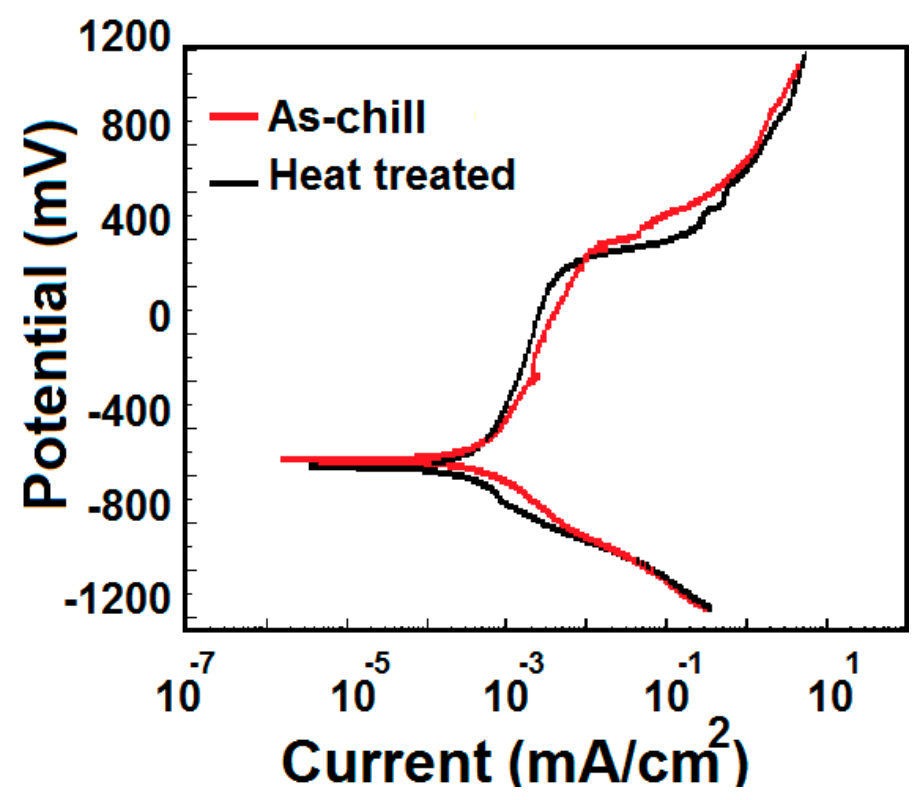

Figure 11. Polarization curves for the Co-20 wt. \% Cr alloys in both, the as-chill cast and the heat treated conditions.

Table 3. Electrochemical parameters obtained from the polarization curves of Co-20 wt. \% Cr alloys polarized in Artificial Saliva Solution.

\begin{tabular}{|c|c|c|c|c|c|}
\hline Co-20 wt. \% Cr (Condition) & $\begin{array}{l}E_{\text {corr }} \\
(\mathrm{mV})\end{array}$ & $\begin{array}{c}I_{\text {corr }} \\
\left(\mathrm{mA} / \mathrm{cm}^{2}\right)\end{array}$ & $\begin{array}{c}E_{\text {pit }} \\
(\mathrm{mV})\end{array}$ & $\begin{array}{c}I_{\mathrm{pit}} \\
\left(\mathrm{mA} / \mathrm{m}^{2}\right)\end{array}$ & $\begin{array}{c}V_{\text {corr }} \\
\text { (mm/year) }\end{array}$ \\
\hline As-cast (present work) & -554.2 & $1 \times 10^{-4}$ & 298.2 & 0.006 & 0.00084 \\
\hline $\begin{array}{l}\text { Heat treated } \\
\text { (present work) }\end{array}$ & -524.19 & $4.22 \times 10^{-4}$ & 384.16 & 0.014 & 0.00356 \\
\hline Co-Cr as-cast [17] & & & & & 1.26 \\
\hline Co-Cr as-cast [29] & & & & & 5.43 \\
\hline Co-Cr Heat treated [29] & & & & & 0.061 \\
\hline
\end{tabular}

\section{Discussion}

\subsection{Phases}

Figure 12 shows a map of the various phases found as a function of the applied cooling rates and $\mathrm{Cr}$ contents where the presence of FCC $\gamma$-Co phase/HCP $\varepsilon$-Co phase is observed even for eutectic compositions. In the case of investment casting $\mathrm{Co}-\mathrm{Cr}$ alloys, a highly inhomogeneous structure is expected to form with large-grained cored dendrites and Co-rich regions. In particular, the interdendritic regions can contain various quaternary $\mathrm{Co}$-rich, $\mathrm{Cr}$-rich, and $\mathrm{Cr}$ - and $\mathrm{Mo-rich}$ phases [30]. The microstructures found in the rapidly solidified Co-35 wt. \% Cr, Co-40 wt. \% Cr and Co-44 wt. \% Cr alloys are in agreement with the ones reported by other workers [21,31,32], but for the binary Co-Cr system. 


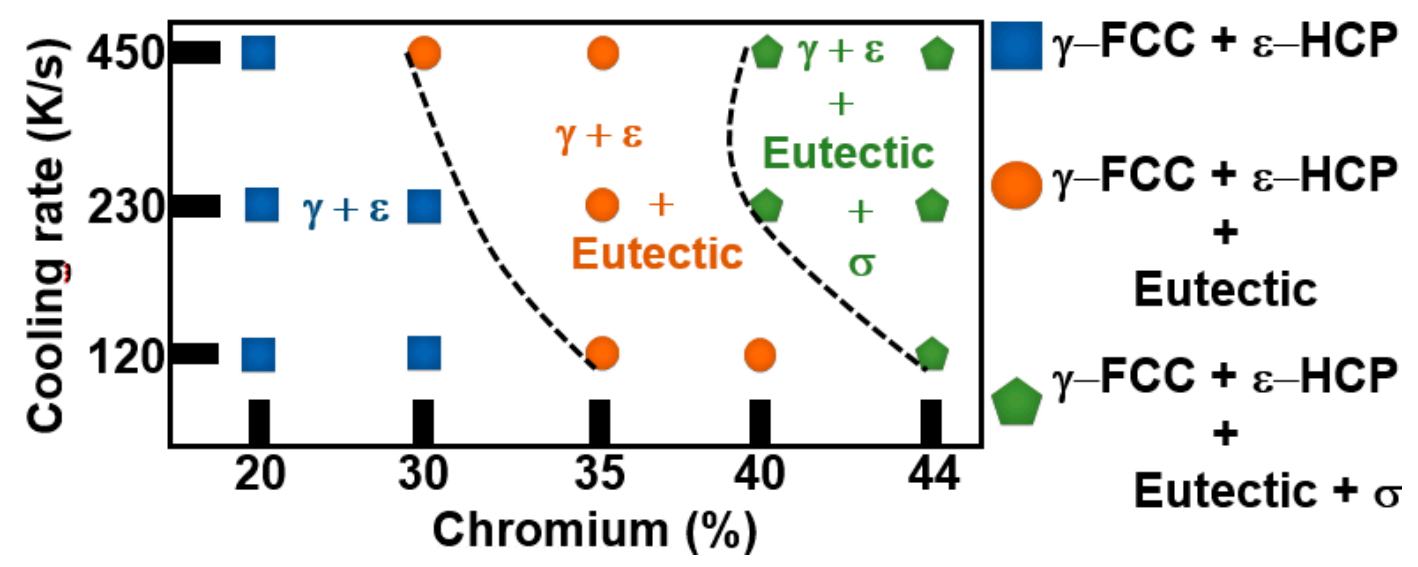

Figure 12. Mapping of the various phases found including intermetallics and the eutectic constituent as a function of cooling rates and $\% \mathrm{Cr}$.

From this work, it is evident that rapid solidification either reduces or inhibits segregation at $\mathrm{Cr}$ contents below $30 \mathrm{wt}$. \% (see Figure 13). Nevertheless, as the Cr-content increases, the columnar dendritic structure becomes heavily segregated at the interdendritic locations. X-ray diffraction determinations confirmed the presence of the eutectic constituent and of the $\sigma$-phase for chromium contents $>30 \mathrm{wt}$. \% (see Figure $5 \mathrm{c}, \mathrm{d}$ ). In addition, X-ray intensity peaks corresponding to the FCC $\gamma$-Co phase and HCP $\varepsilon$-Co phase were identified. Moreover, as the $\mathrm{Cr}$ content increases in the as-cast alloys, a reduction in the primary dendrite arm spacing was observed (see Figure 3). This effect is concomitant with an increase in interdendritic segregation (Co-40 and $44 \mathrm{wt} . \% \mathrm{Cr}$ alloys) and with the precipitation of both, the eutectic and the $\sigma$-phase in agreement with other reports [21]. In contrast, in conventionally solidified as-cast microstructures the interdendritic regions are rather wide with spacings oscillating between $7 \mu \mathrm{m}$ and $18 \mu \mathrm{m}$ [7,31-33], as shown in Figure 4.
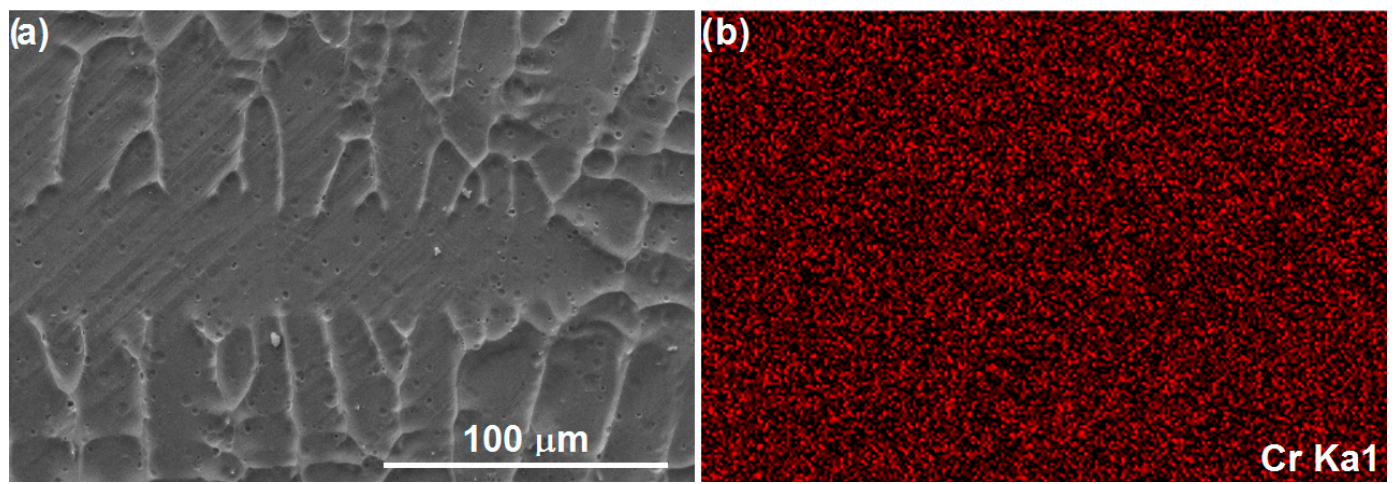

Figure 13. (a) SEM micrograph of the as-chill cast Co-20 wt. \% Cr directionally solidified alloy showing a part of columnar dendrites, (b) X-ray mapping of $\mathrm{Cr}$ (chromium).

\subsection{HCP and FCC Phases}

In this work, it was found that the HCP $\varepsilon$-Co phase was able to form in all the rapidly solidified alloys regardless of the $\mathrm{Cr}$ content. According to the published literature [34], it is well-known that the athermal $\mathrm{HCP} \varepsilon$-Co phase occurs by a martensitic transformation from the high temperature stable FCC $\gamma$-Co phase. The development of athermal $\varepsilon$-martensite is expected to be favored by rapid cooling from the $\gamma$-Co phase [34]. Nevertheless, in conventionally investment solidified Co-Cr-Mo-C alloys the reported amounts of precipitated $\varepsilon$-martensite have been found to be relatively small, not exceeding 20 vol. \%, in most cases [35,36]. A maximum of 64 vol. \% was reported in $80 \mu \mathrm{m}$ water atomized 
Co-Cr-Mo powders (Figure 6) [25]. The amounts of athermal $\varepsilon$-martensite are strongly influenced by the annealing temperatures, with increasing volume fractions found in alloys annealed at increasing temperatures [34]. In contrast, under the cooling conditions achieved during chill casting of $\mathrm{Co}-\mathrm{Cr}$ alloys, the amounts of precipitated athermal $\varepsilon$-martensite exceeded 80 vol. \% as seen in Table 2 .

SEM and TEM observations of the exhibited microstructures (see Figures 7 and 8 ) are consistent with the ones reported by Rajan [37] for HCP martensite. From the electron diffraction pattern, it is found that the FCC $\gamma$-Co possesses a [11] zone axes, and a [01Ī0] one for the HCP $\varepsilon$-Co. In addition, these phases possess a $(1 \overline{\mathrm{I}} 1)$ | I (0002) orientation relationship. From Figure $8 \mathrm{a}$ it is evident that the FCC $\gamma$-Co phase is located between fine HCP $\varepsilon$-martensite plates. Apparently, a high density of $\varepsilon$-martensite plates nucleated and grew at expenses of the austenitic matrix, leaving residual $\gamma$-Co phase films in-between $\varepsilon$-martensite plates. Thus, copious nucleation of athermal $\varepsilon$-martensite seems to be strongly favored by the rapid cooling effects imposed on these alloys. According to Jones [38], it is expected that rapid solidification will lead to a high density of vacancies and a high volume of planar defects (stacking faults), favoring a martensitic transformation. The outcome of this work indicates that the $\gamma$ to $\varepsilon$ martensitic transformation is dominant under rapid solidification conditions with over $80 \mathrm{vol}$. \% $\varepsilon-\mathrm{HCP}$ phase developing in most of the investigated alloys.

\subsection{Mechanical Properties}

From the outcome of this work, a Co-20 wt. \% Cr alloy was chosen for additional testing, as this alloy exhibited minimal or no segregation with no intermetallic phases. Accordingly, the mechanical properties of this alloy were investigated before and after an isothermal heat treatment at $1003.15 \mathrm{~K}$ for $60 \mathrm{~min}$. The heat treatment was intended to remove any internal stresses associated with the alloy rapid solidification. Figure 14 shows the effect of the isothermal heat treatment on the exhibited microstructure in the Co-20 wt. \% Cr alloy. Notice that in this condition the morphology of the $\varepsilon$-martensite is rather different from the one in the as-cast condition, in agreement with published reports $[39,40]$.

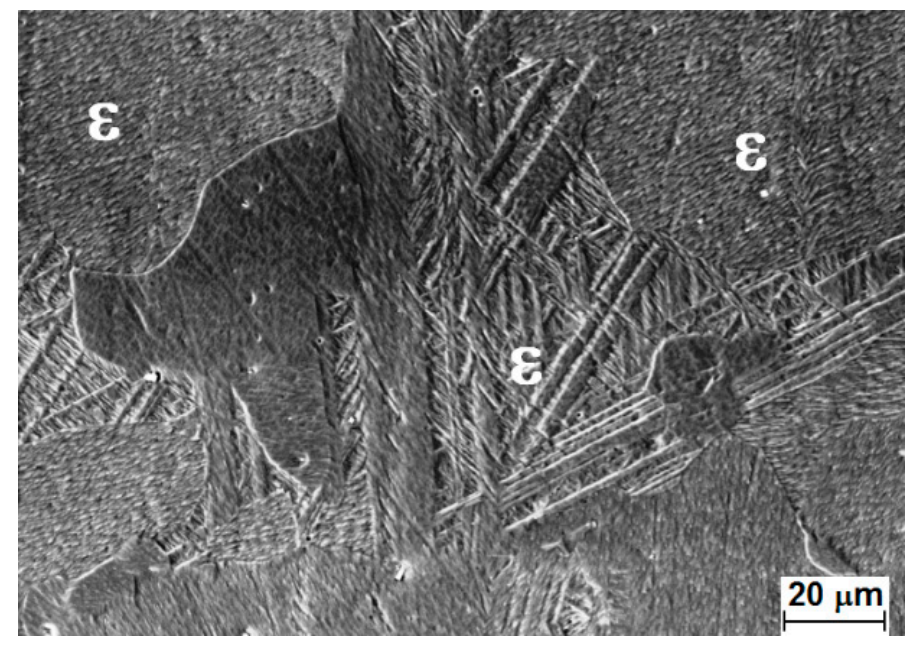

Figure 14. As-heat-treated microstructure showing isothermally developed $\mathrm{HCP} \varepsilon$-Co plates.

Figure 15a is a TEM micrograph clearly showing embedded numerous stacking faults together with various $\varepsilon$-martensite bands and a high density of dislocations. The corresponding diffraction pattern (Figure 15b) shows that the zone axes for the HCP $\varepsilon$-Co phase is now [1]. 


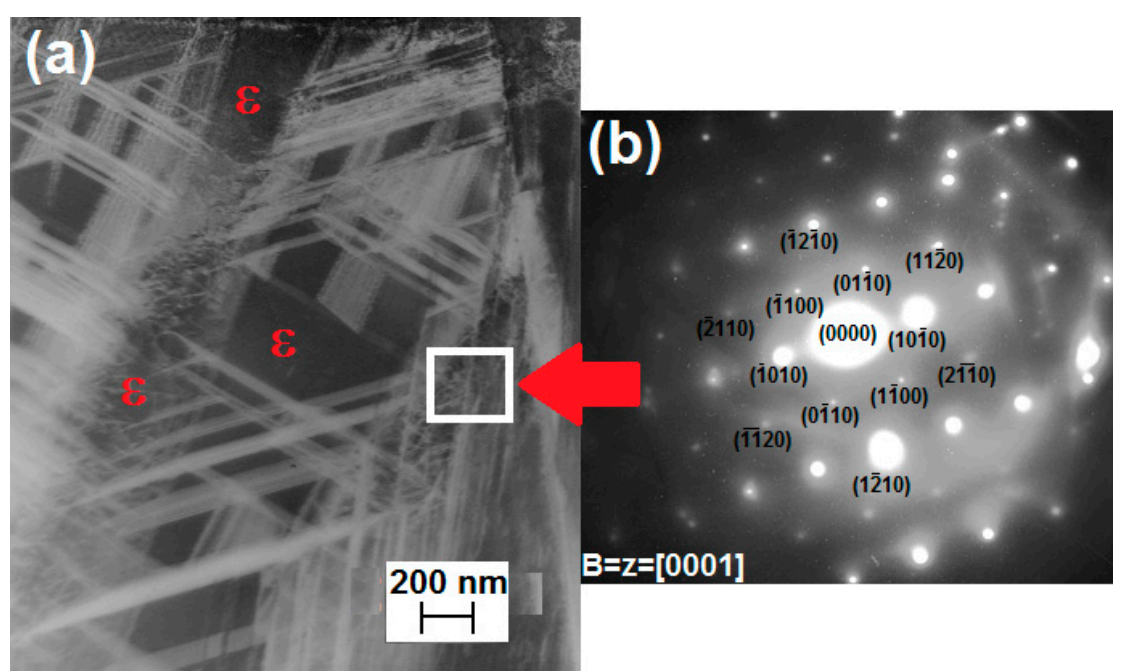

Figure 15. Heat-treated Co-20 wt. \%Cr: (a) TEM micrograph showing HCP $\varepsilon$-Co plates and (b) corresponding electron diffraction pattern.

In particular, notice that the dendritic structure tends to be erased by the isothermal heat treatment. In addition, the amount of $\varepsilon$-martensite increases (from 85 vol. \% in the as-cast condition to 96 vol. \% after heat treating, see Figure 16). Apparently, under these conditions, isothermal $\varepsilon$-martensite develops from the athermal one and also from the remaining FCC $\gamma$-Co phase. In addition (see Figure 15a), there is an apparent thickening of $\varepsilon$-martensite plates and the confinement of the FCC $\gamma$-Co phase to highly localized narrow regions (see Figure 8a).

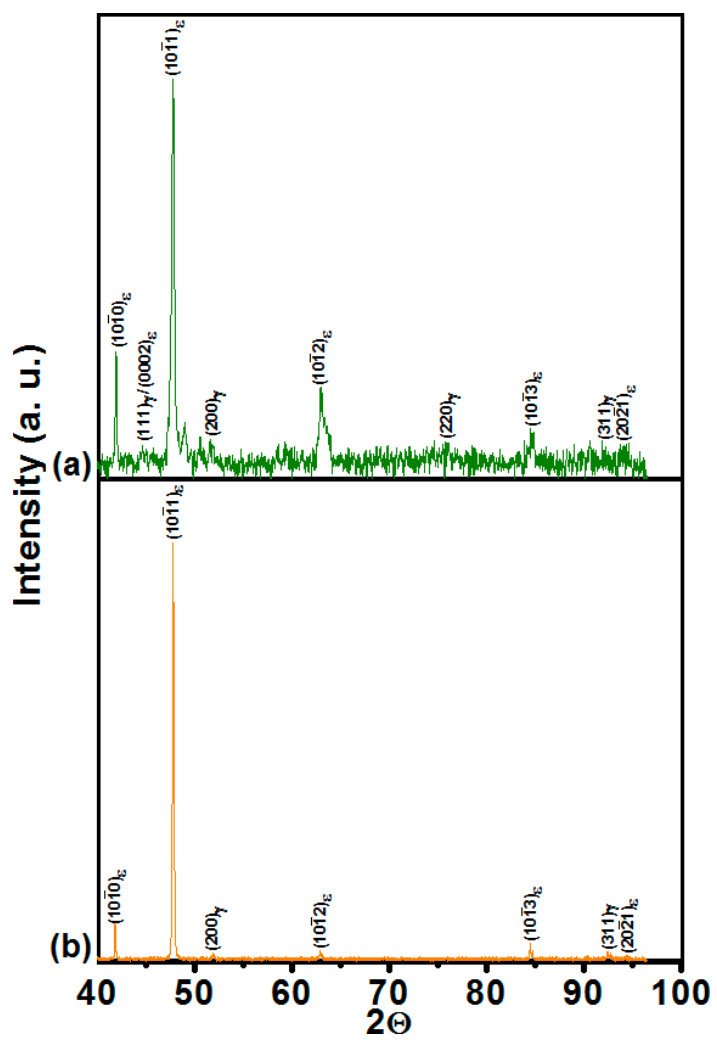

Figure 16. Diffraction patterns of Co-20 wt. \% $\mathrm{Cr}$ alloy: (a) as-chill cast condition; (b) heat-treated condition. 
A drastic improvement in the alloy ductility was also achieved after the isothermal heat treating (i.e., up to $26 \%$ elongation), which is over a 10 -fold increase when compared with the alloy in the as-cast condition $[21,22,41,42]$. These elongation values are rather similar to the ones reported for other Co-alloys heat treated at high temperatures [41], forged [43] or hot rolled [44], as shown in Figure 17. Notice from the fracture modes that the effect of the prior columnar dendritic structure was not dominant in the final fracture path in the heat-treated condition (see Figure 10). Moreover, the exhibited brittle fracture path in the as-cast alloy is not related to inhomogeneous solute distribution as the alloy did not exhibit any significant segregation effects nor precipitation of any intermetallic phases. Thus, the outcome of this work indicates that rapid solidification in $\mathrm{Co}-\mathrm{Cr}$ alloys promotes microstructural homogeneity. Moreover, through alloy heat treating, the resultant mechanical properties are drastically improved, becoming highly attractive for potential biomedical applications.

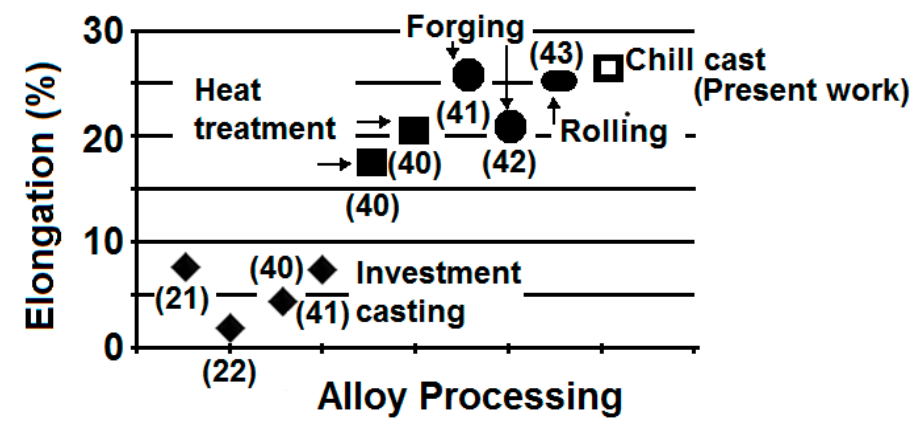

Figure 17. Percent elongation of Co-alloys as a function of alloy processing.

\subsection{Corrosion Properties}

The experimental Co-20 wt. \% Cr was found to possess an optimum combination of strength and ductility for some potential biomedical applications. Yet another critical alloy requirement is related to a high biocompatibility in the human body, particularly high corrosion resistance. Hence, preliminary testing was carried out to assess the alloy corrosion behavior. This is primarily motivated by the potentially harmful effects associated with the high cytotoxicity of the byproducts generated during the corrosion process [17]. From the corrosion results (see Figure 11 and Table 3) it was found that the corrosion properties of the Co-20 wt. \% Cr alloy in the as-cast condition are slightly superior to the ones obtained after the heat treatment. In turn, this confirms that the as-cast alloy is highly homogeneous as there are no preferential defects such as intermetallics or alloy segregation that can trigger severe or localized corrosion. Moreover, in both cases, the exhibited corrosion rates are appreciably lower than the ones corresponding with those reported for other Co-Cr alloys [29] under similar corrosion conditions in artificial saliva. Thus, it is evident that through microstructural control using rapid solidification (i.e., suppression of interdendritic segregation and intermetallic precipitation) it is plausible to design a Co-Cr alloy with unique properties for applications such as in dental materials.

\section{Conclusions}

(1) In this work an alternative solidification process is proposed that can be used to produce $\mathrm{Co}-\mathrm{Cr}$ alloys with unique microstructures.

(2) Through the use of wedge-shaped copper molds, rapid solidification regimes were achieved in the solidified alloys.

(3) In the eutectic composition (Co-44 wt. \% $\mathrm{Cr}$ alloy) there were some constitutional changes; as a result of rapid solidification, the FCC $\gamma$-Co and HCP $\varepsilon$-Co solid solution phases were able to form outside their equilibrium limits (solid solubility extension). In addition, dendrite refinement and elimination or reduction of interdendritic segregation for Co-20, 30, 35, 40, and 44 wt. \% 
Cr alloys was observed, which can be considered as one of the microstructural effects due to rapid solidification.

(4) Rapid solidification effects, such as excess vacancies and the development of numerous stacking faults and corresponding intersections, strongly favored the athermal $\varepsilon$-martensite transformation. Amounts of athermal $\varepsilon$-martensite exceeding $80 \mathrm{vol}$. \% were induced at all of the cooling rates imposed on most of the alloys in the as-cast condition.

(5) An isothermal heat treatment below the $\gamma-\varepsilon$ phase transformation temperature was implemented in the Co-20 wt. \% Cr alloy. In turn, the mechanical strength was found to improve by over $40 \%$ whereas the alloy ductility exhibited over a 10-fold increase when compared with the alloy in as-cast condition. SEM and TEM characterization revealed that in the as-cast condition the resultant microstructure is composed of fine athermal $\varepsilon$-martensite plates inside directionally solidified columnar dendrites. After aging, the morphology undergoes a change due to the isothermal transformation of $\mathrm{HCP} \varepsilon$-martensite as confirmed by $\mathrm{X}$-ray diffraction data.

(6) Potentiodynamic polarization curves indicated that the Co-20 wt. \% Cr alloy exhibited the lowest corrosion rates when compared with other Co-based alloys currently in use. In turn, preliminary results indicate that the combination of mechanical strength and corrosion resistance exhibited by this alloy processed by rapid solidification makes it attractive for potential applications as a biomaterial.

Acknowledgments: The authors would like to express their gratitude for the technical work of A. Tejeda, C. Flores-Morales C. Zorrilla. We acknowledge the financial support from UNAM/PAPIIT IT100316.

Author Contributions: Julio A. Juarez-Islas designed the experiments; Julio A. Juarez-Islas, Ana L. Ramirez-Ledesma and Hugo F. Lopez analyzed the results; the paper was written by all authors.

Conflicts of Interest: The authors declare no conflict of interest.

\section{References}

1. Vandamme, N.S.; Topoleski, L.D.T. Control of surface morphology of carbide coating on Co-Cr-Mo implant alloy. J. Mater. Sci. Mater. Med. 2005, 16, 647-654. [CrossRef] [PubMed]

2. Podrez-Radziszewska, M.; Haimann, K.; Dudziński, W.; Morawska-Sołtysik, M. Characteristic of intermetallic phases in cast dental CoCrMo alloy. Arch. Foundry Eng. 2010, 10, 51-56.

3. Lee, S.H.; Nomura, N.; Chiba, A. Significant improvement in mechanical properties of biomedical Co-Cr-Mo alloys with combination of N addition and Cr-enrichment. Mater. Trans. JIM 2008, 49, 260-264. [CrossRef]

4. Niinomi, M.; Nakai, M.; Hieda, J. Development of new metallic alloys for biomedical applications. Acta Biomater. 2012, 8, 3888-3903. [CrossRef] [PubMed]

5. Hedberg, Y.S.; Qian, B.; Shen, Z.; Virtanen, S.; Odnevall-Wallinder, I. In vitro biocompatibility of CoCrMo dental alloys fabricated by selective laser melting. Dent. Mater. 2014, 30, 525-534. [CrossRef] [PubMed]

6. Berlin, R.M.; Gustavson, L.J.; Wang, K.K. Influence of post processing on the mechanical properties of investment cast and wrought Co-Cr-Mo alloys. In Cobalt Base Alloys for Biomedical Applications; Disegi, J.A., Kennedy, R.L., Pilliar, R., Eds.; ASTM International: West Conshohocken, PA, USA, 1999; pp. 62-70.

7. Kaiser, R.; Williamson, K.; O’Brien, C.; Browne, D.J. Effects of section size, surface cooling conditions, and crucible material on microstructure and as-cast properties of investment cast Co-Cr biomedical alloy. Metall. Mater. Trans. A 2013, 44A, 5333-5342. [CrossRef]

8. Lee, S.H.; Takahashi, E.; Nomura, N.; Chiba, A. Effect of carbon addition on microstructure and mechanical properties of a wrought Co-Cr-Mo implant alloy. Mater. Trans. JIM 2006, 47, 287-290. [CrossRef]

9. Salinas-Rodriguez, A.; Rodriguez-Galicia, J.L. Deformation behavior of low-carbon Co-Cr-Mo alloys for low-friction implant applications. J. Biomed. Mater. Res. 1996, 31, 409-419. [CrossRef]

10. Mani, A.; Salinas-Rodriguez, A.; Lopez, H.F. Deformation induced FCC to HCP transformation in a Co-27Cr-5Mo-0.05C alloy. Mater. Sci. Eng. A 2011, 528A, 3037-3043. [CrossRef]

11. Lee, S.H.; Takahashi, E.; Nomura, N.; Chiba, A. Effect of heat treatment on microstructure and mechanical properties of $\mathrm{Ni}$ - and C-free Co-Cr-Mo alloys for medical applications. Mater. Trans. JIM 2005, 46, 1790-1793. [CrossRef] 
12. Paul, B.; Kapoor, R.; Chakravartty, J.K.; Bidaye, A.C.; Sharma, I.G.; Suri, A.K. Hot working characteristics of cobalt in the temperature range 600-950 ${ }^{\circ} \mathrm{C}$. Scr. Mater. 2009, 60, 104-107. [CrossRef]

13. Mori, M.; Yamanaka, K.; Sato, S.; Wagatsuma, K.; Chiba, A. Microstructures and mechanical properties of biomedical Co-29Cr-6Mo-0.14N alloys processed by hot rolling. Metall. Mater. Trans. A 2012, 42A, 3108-3119. [CrossRef]

14. ASTM F562-13. Standard Specification for Wrought 35Cobalt-35Nickel-20Chromium-10Molybdenum Alloy for Surgical Implant Applications (UNS R30035); ASTM International: West Conshohocken, PA, USA, 2013.

15. Niinomi, M. Recent research and development in titanium alloys for biomedical applications and healthcare goods. Sci. Technol. Adv. Mater. 2003, 4, 445-454. [CrossRef]

16. Roach, M. Base metal alloys used for dental restorations and implants. Dent. Clin. N. Am. 2007, 51, 603-627. [CrossRef] [PubMed]

17. Saravanan, G.; Mohan, S. Structure, composition and corrosion resistance studies of Co-Cr alloy electrodeposited from deep eutectic solvent (DES). J. Alloy. Compd. 2012, 522, 162-166. [CrossRef]

18. Taylor, R.N.J.; Waterhouse, R.B. A study of the ageing behaviour of a cobalt based implant alloy. J. Mater. Sci. 1983, 18, 3265-3280. [CrossRef]

19. Giancchi, J.V.; Morando, C.N.; Fornaro, O.; Palacio, H.A. Microstructural characterization of as-cast biocompatible Co-Cr-Mo alloys. Mater. Charact. 2011, 62, 53-61. [CrossRef]

20. Zhuang, L.Z.; Langer, E.W. Effects of alloy additions on the microstructures and tensile properties of cast Co-Cr-Mo alloy used for surgical implants. J. Mater. Sci. 1989, 24, 4324-4330. [CrossRef]

21. Zhuang, L.Z.; Langer, E.W. Effects of cooling rate control during the solidification process on the microstructure and mechanical properties of cast Co-Cr-Mo alloy used for surgical implants. J. Mater. Sci. 1989, 24, 381-388. [CrossRef]

22. Montero-Ocampo, C.; Talavera, M.; Lopez, H. Effect of alloy preheating on the mechanical properties of as-cast Co-Cr-Mo-C alloys. Metall. Mater. Trans. A 1999, 30A, 611-620. [CrossRef]

23. Mineta, S.; Alfirano; Namba, S.; Yoneda, T.; Ueda, K. Phase and formation/dissolution of precipitates in biomedical Co-Cr-Mo alloys with nitrogen addition. Metall. Mater. Trans. A 2013, 44A, 494-503. [CrossRef]

24. Pilliar, R.M. Metallic biomaterials. In Biomedical Materials; Narayan, R., Ed.; Springer: New York, NY, USA, 2009; pp. 41-82.

25. Song, C.; Park, H.; Lopez, H.F. Development of athermal and isothermal $\varepsilon$-martensite in atomized Co-Cr-Mo-C implant alloy powders. Metall. Mater. Trans. A 2006, 37A, 3197-3204. [CrossRef]

26. Sage, M.; Guillaud, C. Méthode d'analyse quantitative des variétés allotropiques du cobalt pre les Rayons X. Rev. Metall. 1950, 49, 139-145.

27. Shi, L.; Northwood, D.O.; Cao, Z. Alloy design and microstructure of a biomedical Co-Cr alloy. J. Mater. Sci. 1993, 28, 1312-1315. [CrossRef]

28. Huang, P.; Lopez, H.F. Strain induced $\varepsilon$-martensite in a Co-Cr-Mo alloy: Grain size effects. Mater. Lett. 1999, 39, 244-248. [CrossRef]

29. Yamanaka, K.; Mori, M.; Chiba, A. Enhanced Mechanical Properties of As-Forged Co-Cr-Mo-N Alloys with Ultrafine-Grained Structures. Metall. Mater. Trans. A 2012, 43A, 5243-5257. [CrossRef]

30. Sharma, M.; Ramesh-Kumar, A.V.; Singh, N.; Adya, N.; Saluja, B. Electrochemical corrosion behavior of dental/implant alloys in artificial saliva. J. Mater. Eng. Perform. 2008, 17, 695-701. [CrossRef]

31. Angelini, E.; Zucchi, F. In vitro corrosion of some Co-Cr and Ni-Cr alloys used for removable partial dentures: Influence of heat treatments. J. Mater. Sci. Mater. Med. 1991, 2, 27-35. [CrossRef]

32. Tomas, H.; Freire, A.P.; Abrantes, L.M. Cast Co-Cr alloy and pure chromium in proteinaceous media: An electrochemical characterization. J. Mater. Sci. Mater. Med. 1994, 5, 446-451. [CrossRef]

33. Lawrence-Kats, J. Orthopedic applications. In Biomaterials Science: An Introduction to Materials in Medicine; Ratner, B.D., Hoffman, A.S., Schoen, F.J., Lemons, J.E., Eds.; Elsevier: London, UK, 2004; pp. 335-346.

34. Bogno, A.; Nguyen-Thi, H.; Reinhart, G.; Billia, B.; Baruchel, J. Growth and interaction of dendritic equiaxed grains: In situ characterization by synchrotron X-ray radiography. Acta Mater. 2013, 61, 1302-1315. [CrossRef]

35. Lopez, H.F.; Saldivar, A.; Huang, P. Development and properties of $\varepsilon$-martensite in Co-Cr-Mo alloys for biomedical applications. In Properties of Complex Inorganic Solids 2; Meike, A., Gonis, A., Turchi, P., Rajan, K., Eds.; Kluwer Academic/Plenum Publishers: New York, NY, USA, 1999; pp. 307-325.

36. Huang, P.; Salinas-Rodriguez, A.; Lopez, H.F. Tribological behaviour of cast and wrought Co-Cr-Mo implant alloys. Mater. Sci. Technol. 1999, 15, 1324-1330. 
37. Saldivar-Garcia, A.; Mani-Medrano, A.; Salinas-Rodriguez, A. Effect of solution treatments on the fcc/hcp isothermal martensitic transformation in Co-27Cr-5Mo-0.05C aged at $800{ }^{\circ} \mathrm{C}$. Scr. Mater. 1999, 40, 717-722. [CrossRef]

38. Rajan, K. Phase Transformations in a Wrought Co-Cr-Mo-C Alloy. Metall. Mater. Trans. A 1982, 13A, 1161-1166. [CrossRef]

39. Jones, H. Rapid Solidification of Metals and Alloys; The Institution of Metallurgists: London, UK, 1982; pp. 1-80.

40. Saldivar, A.J.; Lopez, H.F. Role of aging on the martensitic transformation in a cast cobalt alloy. Scr. Mater. 2001, 45, 427-433. [CrossRef]

41. Saldivar-Garcia, A.J.; Mani-Medrano, A.; Salinas-Rodriguez, A. Formation of Hcp martensite during the isothermal aging of an Fcc Co-27Cr-5Mo-0.05C orthopedic implant alloy. Metall. Mater. Trans. A 1999, 30A, 1177-1184. [CrossRef]

42. Vander-Sande, J.B.; Coke, J.R.; Wulff, J. A transmission electron microscopy the mechanisms of strengthening in heat-treated Co-Cr-Mo-C alloys. Metall. Mater. Trans. A 1976, 7A, 389-397. [CrossRef]

43. Lashgari, H.R.; Zangeneh, S.; Hasanabadi, F.; Saghafi, M. Microstructural evolution during isothermal aging and strain-induced transformation followed by isothermal aging in Co-Cr-Mo-C alloy: A comparative study. Mater. Sci. Eng. A 2010, 527A, 4082-4091. [CrossRef]

44. Chiba, A.; Kumagai, K.; Takeda, H.; Nomura, N. Mechanical properties of forged low Ni and C-containing Co-Cr-Mo. Mater. Sci. Forum 2005, 475-479, 2317-2322. [CrossRef]

(C) 2016 by the authors; licensee MDPI, Basel, Switzerland. This article is an open access article distributed under the terms and conditions of the Creative Commons Attribution (CC-BY) license (http:/ / creativecommons.org/licenses/by/4.0/). 